\title{
Aproximación a los enfoques de aprendizaje, el pensamiento reflexivo, y las creencias epistemológicas: un enfoque de variables latentes
}

\author{
Huy P. Phan
}

Facultad de Educación, Universidad del Pacífico Sur, Suva

Fiji

phan_h@usp.ac.fj 


\section{Resumen}

Introducción. El trabajo del pensamiento reflexivo (Mezirow, 1991, 1998) y las creencias epistemológicas (Schommer, 1990, 1993; Schommer-Aikins, Duell y Hutter, 2005) se reconoce cada vez más por su papel en el aprendizaje académico de los alumnos. Además, los enfoques de aprendizaje de los alumnos también se consideran factores que contribuyen para predecir el rendimiento académico de los mismos. Muy pocos estudios hasta la fecha han integrado estos tres marcos en un solo estudio. Este trabajo trata dos estudios que se llevaron a cabo a lo large de doce meses, en matemáticas y en estudios curriculares, examinando las relaciones entre las creencias epistemológicas, los enfoques de aprendizaje, el pensamiento reflexivo, y el rendimiento académico de los alumnos.

Método. El Estudio 1 examinó, para el primer curso de matemáticas $(N=352: 152$ mujeres, 200 varones), los enfoques de aprendizaje-profundo y superficial--, las cuatro etapas del pensamiento reflexive, y el rendimiento académico de los alumnos. El Estudio 2 trató con alumnos del tercer curso de estudios curriculares $(N=332$ : 146 females, 185 males), y empleó el análisis de coeficientes de sendero para demostrar que los enfoques de aprendizaje profundos, las creencias epistemológicas, y el pensamiento reflexive predecían el rendimiento académico.

Resultados. Para el Estudio 1, el análisis structural lineal indicó que un enfoque de aprendizaje superficial predicía la acción habitual, y un enfoque de aprendizaje profundo predecía la comprensión y la reflexión crítica. El enfoque de aprendizaje profundo, la acción habitual, y la reflexión crítica también predecían el rendimiento académico. Los resultados para el Estudio 2 indicaron que los enfoques de aprendizaje profundos también predecían la acción habitual y la reflexión. Además, las creencias epistemológicas influían en los enfoques de aprendizaje as como en las cuatro etapas del pensamiento reflexive.

Discusión o Conclusión. Los hallazgos de los dos estudios son significativos, pues aportan de forma teórica a la literatura existente, así como proporcionan implicaciones practices para los docentes en cuanto a las relaciones entre las creencias epistemológicas, los enfoques de aprendizaje, el pensamiento reflexivo, y el rendimiento académico.

Palabras clave: pensamiento reflexivo, creencias epistemológicas, enfoques de aprendizaje, análisis estructural 